\title{
Crisis Planning for Online Students: Lessons Learned from a Major Disruption
}

\author{
Peggy C Holzweiss, Daniel W Walker, Ruth Chisum, and Thomas Sosebee \\ Sam Houston State University
}

\begin{abstract}
While institutions have crisis management plans, they are often focused on face-to-face students and the physical campus. In this case study, researchers investigated the crisis response for online students at one institution after Hurricane Harvey hit the Houston, Texas area in the fall of 2017. While face-to-face students were not severely impacted, more than a thousand online students were in the impact zone and in danger of dropping out. With financial resources and student retention at risk, campus leaders approved a strategy to delay online courses for several weeks. This study examines the experiences of the frontline staff who implemented the plan. Findings suggest that institutions need a proactive crisis plan for online students that includes understanding where this population resides, how different campus units can provide support in a crisis, who should lead the crisis response, and what kind of care can be offered to the frontline responders during the crisis period.
\end{abstract}

Keywords: crisis management, academic continuity, online students, qualitative research, case study

Holzweiss, P.C., Walker, D.W., Chisum, R., \& Sosebee, T. (2020). Crisis planning for online students: Lessons learned from a major disruption. Online Learning, 24(2), 22-37. https://doi.org/10.24059/olj.v24i2.2135

\section{Crisis Planning for Online Students: Lessons Learned from a Major Disruption}

Zdziarski (2006) defined a crisis as "an event, often sudden or unexpected, that disrupts the normal operations of the institution or its educational mission and threatens the well-being of personnel, property, financial resources, and/or reputation of the institution" (p. 4). The definition further examined different types of events that could impact a college campus including disasters, which involve the campus and community; crises, which occur just on the campus; and critical incidents, which involve smaller units within the campus. Researchers urged administrative leaders to make crisis planning a priority so the campus is well-prepared for any incident (Harper, Paterson, \& Zdziarski, 2006; Mitroff \& Anagnos, 2001; Rollo \& Zdziarski, 2007; Zdziarski, 2006).

Despite more than a decade of emphasizing the need for planning, crisis response on college campuses has been described as mostly reactive rather than proactive (Catullo, Walker, \& 
Floyd, 2009; Wang \& Hutchins, 2010). While a few crisis response strategies are well-planned and practiced such as building evacuations and recovery of data after technology failures, college leaders often neglect scenarios that could put economic, informational, physical, and human resources at risk (Mitroff \& Anagnos, 2001).

For instance, after Hurricane Katrina hit the Gulf Coast in 2005, several campuses in the impact zone lost more than half of their student enrollment (L'Orange, 2010). This represents a significant financial loss for an institution, especially now that tuition and fees have become a primary revenue stream for most colleges (The Chronicle of Higher Education Almanac, 2018). While the immediate physical safety of students and campus personnel is a priority for any crisis, these events also tend to cause disruption in the academic functions of the campus. Creating academic continuity plans can help students continue their education, maintain retention rates, and keep campus financial resources stable. L'Orange (2010) explains that most crisis situations have short-term impacts for students and can be mitigated when clear planning and cooperation among different units occurs.

The purpose of this study was to examine what happened at one institution when a disaster interrupted the continuity of online courses. The study addresses what occurred, how a crisis response developed, how the response helped online students stay enrolled during a challenging time, and what effect the situation had on the frontline staff. The experiences of the frontline staff can inform crisis planning on college campuses and identify possible obstacles and solutions for supporting online students experiencing a crisis.

\section{Review of Relevant Literature}

\section{Theoretical Framework}

Zdziarski (2006) explained that crisis management in higher education settings should consist of an iterative process rather than merely tasks to perform. The author examined several models of crisis management then proposed a five-step process specifically designed for college campuses consisting of (1) prevention and mitigation, (2) planning, (3) response, (4) recovery, and (5) learning.

The first step, prevention and mitigation, encourages campus leaders to identify possible crisis events then find ways to reduce the likelihood of their occurrence or the associated risks (Zdziarski, 2006). The author suggests that this step is the most commonly neglected part of the crisis management process but is the most critical for reducing the impact of a crisis. The next three steps - planning, response, and recovery - represent the typical crisis response on college campuses. Leaders determine a few crisis events most likely to occur then develop a strategy for addressing them, implement the strategy when a crisis occurs, and help the campus community through the aftermath until normal campus functions are possible. The final step of learning prompts leaders to assess what occurred in a crisis and evaluate what could be improved in future crisis management activities (Zdziarski, 2006).

Zdziarski's (2006) model for higher education crisis management is a helpful lens through which to view the literature regarding academic continuity challenges involving crises in the online environment. Existing research, while limited, addresses three primary topics relating to online education in a crisis: (1) using online technology to assist face-to-face students during a crisis, (2) 
challenges in using the online environment for crisis response, and (3) crisis planning for online students. All of the literature is reviewed for alignment with the Zdziarski (2006) model.

\section{Using Online Technology to Assist Face-to-Face Students during a Crisis}

Only a few studies examined academic continuity following a crisis, and those studies highlighted online instruction as a way for face-to-face (FTF) students to access learning when it was not available on the physical campus. For example, online instruction temporarily replaced FTF instruction when faculty could not appear in person due to personal emergencies (Day, 2015), when students could not reach their classrooms during a teacher's union strike (Regehr, Nelson, \& Hildyard, 2016), when sick students had to remain home during a flu pandemic (Regehr et al., 2016), and when significant natural disasters occurred and campuses were not accessible (Camille, Dennis, Jackson, \& Kenney, 2008; SchWeber, 2008). In all of these studies, online technology became a tool for FTF students to continue their courses during the crisis period. None of the studies consider what happens when online students experience academic disruptions.

While the researchers all provide good examples of the response and recovery steps in crisis management, only two of the four studies highlight situations where the planning step occurred prior to a crisis situation (Day, 2015; Regehr et al., 2016). What all of the researchers offer, however, is an overview of some of the challenges encountered when utilizing online technology to assist in crisis response. Understanding the challenges can help campus leaders improve planning and mitigation for future crisis situations.

\section{Challenges in Using the Online Environment for Crisis Response}

Researchers noted challenges for both students and faculty when moving from a FTF to an online learning environment during a crisis. Students felt unprepared to handle online learning and experienced several negative outcomes as result such as disengagement with course material (Day, 2015; Regehr et al., 2016), difficulties in managing academic demands (Camille et al., 2008), and an increased likelihood of dropping out (Camille et al., 2008; SchWeber, 2008). Instructors struggled with providing quality online instruction (Day, 2015) and needed more training on how to teach in the online environment (Camille et al., 2008).

These challenges emphasize the need for careful preparation and mitigation of crisis situations. With proper support, students and instructors moving into the online learning environment due to a crisis could successfully recover with fewer obstacles. Yet learning from these experiences still leaves out crises that directly impact the online learning environment.

\section{Crisis Planning for Online Students}

Researchers have concluded that while the majority of college campuses have emergency response plans established for specific crisis situations, the plans do not include details for academic continuity (Meyer \& Wilson, 2011; Regehr et al., 2016). And even when online courses are seen as an option for delivering instruction in a crisis, the FTF student population is the only consideration (Camile et al., 2008; Day, 2015; Regehr et al., 2016; SchWeber, 2008). No studies could be identified regarding online students experiencing a crisis. What happens when the student population impacted by a crisis is already taking courses online and their academic continuity is interrupted? With a third of all college students enrolled in at least one online course (Allen \& Seaman, 2017), this growing population represents a significant portion of college enrollment and needs to be better understood for the purposes of crisis response planning. 
This case study research fills a gap in the literature by examining what happened at one college with a substantial online enrollment when a significant natural disaster occurred near the physical campus. While FTF students were not heavily impacted, online students were at immediate risk for stopping their academic progress. To help students stay enrolled, a team of online support personnel created and implemented an academic continuity plan so students could delay their online courses for several weeks. The experiences of these frontline staff identify challenges and best practices for crisis planning regarding online students and their academic continuity.

\section{Methods}

This section includes the contextual background of the institution; the roles and responsibilities of the online support team; a brief overview of the hurricane and its impact; a description of the academic continuity response; explanation of the research design, data collection, and analysis techniques; and limitations of the study.

\section{Institutional Context}

The case study institution is located approximately one hour north of downtown Houston, Texas. Many members of the college community (commuter students, online students, staff, faculty) reside south of the college, towards Houston and its suburbs. In the fall of 2017, close to 21,000 students were enrolled at the institution, with approximately $15 \%$ enrolled in fully online programs (SHSU Institutional Effectiveness, 2018; SHSU Online, 2018). A majority of fully online students resided in the Houston region. The institution provides numerous online programs and courses and up to $80 \%$ of the student population takes at least one online course in any academic term. The online student population includes students enrolled in fully online programs as well as students who may take both FTF and online courses simultaneously. During the fall and spring academic terms, the majority of FTF and online courses at the institution are offered in a traditional 15-week format.

The institution has an online support team provide services to online students and the faculty who teach their courses. These services include instructional design, video production, technology support, graphic design, online system administration, online program marketing, and institutional support for online academic initiatives. The team members are cross-trained and have worked through challenging, large-scale situations together such as university-wide software migrations and the implementation of new learning management systems for the campus. During a typical academic term, the weeks leading up to the first day of class and up to two weeks into the start of the term are the busiest times for the online support team. Instructors need assistance setting up their online courses and troubleshooting problems while students require technological support and guidance on enrolling in and navigating their online courses in the campus learning management system. For the remainder of the academic term, the online support team responds to situational issues, trains instructors for online teaching, and works on projects for specific instructors and campus leaders.

\section{Hurricane Harvey and its Impact}

Fall classes began on Wednesday, August 23, 2017. At this time, Hurricane Harvey was already a named storm in the Gulf of Mexico and approaching the southern Texas coast. Campus leaders followed its progression closely but did not expect the hurricane to severely impact the 
main campus, which is more than a two-hour drive from the Texas coastline. At this geographic distance, the primary concern was damaging winds and localized flooding.

On August 25, 2017, Hurricane Harvey made landfall on the southwestern Texas coastline and slowly worked its way northeast over the Houston region where it stalled for several days. The lingering storm dumped more than 50 inches of rain totaling over 19 trillion gallons of water-the record for the highest total rainfall in the continental U.S. from a single storm (Texas Commission on Environmental Quality, 2018). As a result, the Texas governor declared 54 counties as disaster zones (Harrington, Ramsey, \& Varinsky, 2017).

While the main campus experienced some weather-related issues such as temporary street flooding and water damage to a few buildings, members of the campus community who lived south of the campus were more heavily impacted by the flooding. Entire neighborhoods were completely underwater while others on higher ground became islands with no way to get in or out. Electricity went out throughout the Houston region and internet services were no longer available. News outlets reported that normal functions would not be restored for several weeks in many areas. With such widespread devastation, the campus president suspended all classes for eight days beginning August 28, 2017 so the campus community could have time to recover from the hurricane. There was no emergency plan created for online students, so campus leaders originally made generic announcements that did not differentiate between FTF and online students. For instance, the first official communication about the campus closure did not mention online courses so students were initially unsure if they still needed to attend their online classes (Sam Houston State University, 2017). As students contacted the institution with questions, subsequent messages clarified that online courses were also cancelled for eight days.

At the same time, the online support team assessed the impact of the hurricane for online students. As they reviewed the geographic locations of students taking online courses, it became clear that a significant majority of them resided in the impact zone (Miller, 2018). Figure 1 depicts a close-up view of the Houston region. The Federal Emergency Management Agency (FEMA) provided a map of the flooded areas, indicated in blue and located throughout the impacted region. The white dots represent the geographic locations of the institution's online students during this time. The circled area in light blue at the top of the image is the location of the main campus. As the figure illustrates, students residing closer to the main campus were not heavily impacted but those in the Houston region had an increased chance of being affected by the widespread flooding and its resulting challenges.

With so many students residing in the impact zone, the possibility of mass withdrawals from courses became a critical concern. Students were facing long-term recovery of personal residences, vehicles, and belongings as well as living without electricity and internet for several weeks. Without an immediate plan to support academic continuity, online students could drop their courses as one way of coping. And, if mass withdrawals occurred, the institution could experience severe funding shortages. 


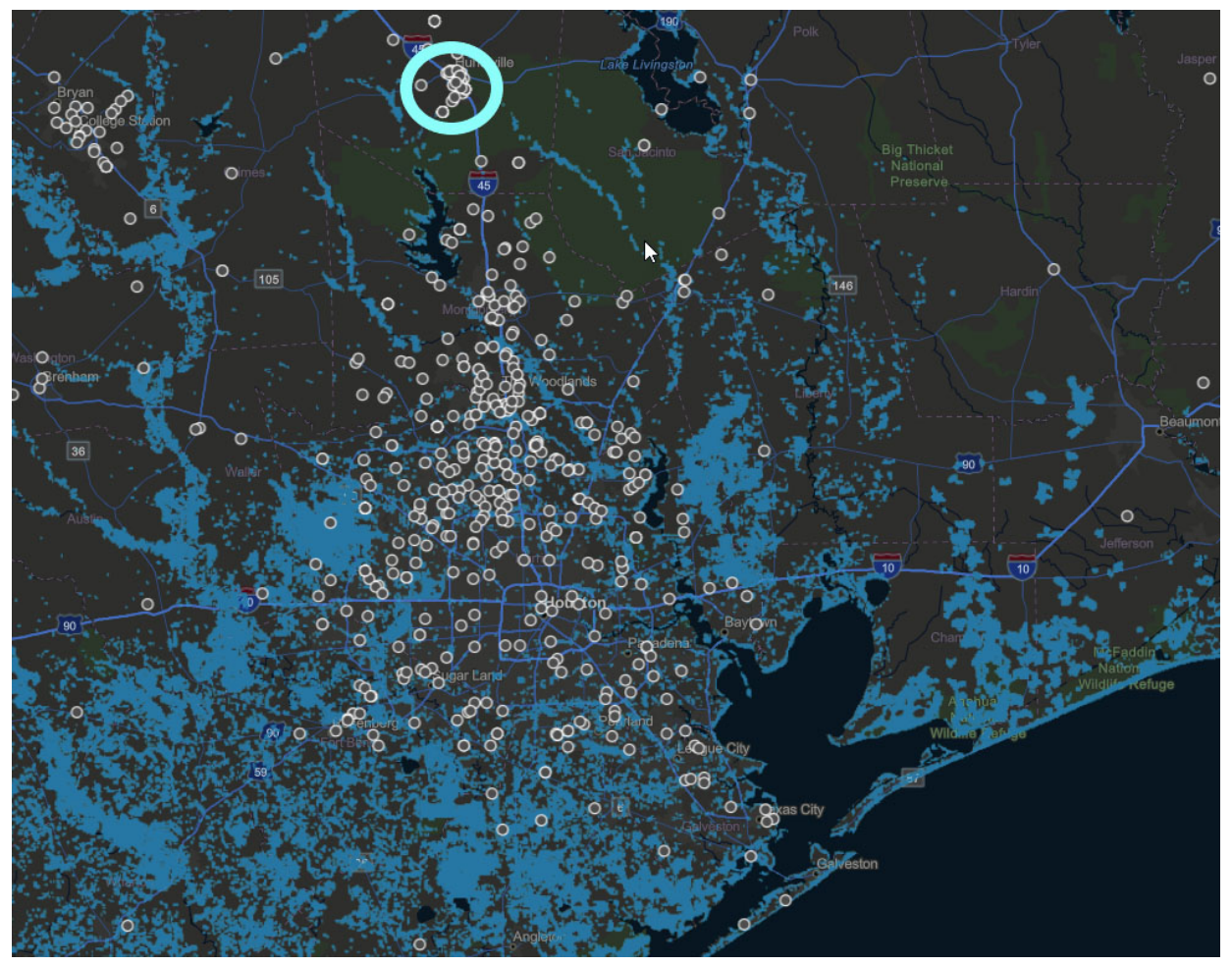

Figure 1. Flooded Areas of Houston, Texas, and Location of Online Students. Adapted from Miller (2018). Reprinted with Permission.

\section{Academic Continuity Plan for Online Students}

In an effort to keep students enrolled for the fall term, the online support team recommended moving from the 15 -week traditional course format to a compressed 7.5 -week course, called "7B." Compressed courses had been previously used at the institution so all technological structures such as enrollment systems and learning management tools already existed and could be used for the crisis response. The proposed plan called for 7B courses to begin in mid-October so students could postpone the start of their online courses for approximately six weeks. Senior campus leaders approved the plan and notifications went out to the campus community while the institution was still closed from the storm.

Faculty members teaching online courses for the fall term were invited to convert their 15 week courses to the 7B format. While some faculty were opposed to offering the shorter courses, monetary incentives of $\$ 1,000$ per instructor were offered and more than 300 instructors volunteered to open $7 \mathrm{~B}$ sections alongside their 15 -week sections. The online support team contacted students who could potentially change sections and offered them the opportunity to enroll in the 7B option. The team collected information from each student then updated the Registrar's Office daily so students' enrollment status could be changed. When the conversion period concluded, the team had created 181 compressed sections with more than 850 students enrolled (Miller, 2018). The team then worked with faculty members to convert their online courses to the compressed format as well as provide support for instructional strategies. This included redesigning syllabi, moving existing course modules into the compressed course structures, and modifying assignments to accommodate the quick timeline. Students who did not 
enroll in the 7B courses had the opportunity to remain in their 15-week courses and work with their instructors for individual accommodations. The team continued to assist faculty and students throughout the term as the $7 \mathrm{~B}$ courses began and challenges were identified.

\section{Case Study Approach, Data Collection, and Data Analysis}

Yin (2018) describes case study research as the examination of a phenomenon involving multiple variables where the phenomena and context are closely intertwined. The topic of this research involves a unique situation where the context is a key factor of the phenomena, making case study methods an appropriate approach. The researchers utilized a single embedded case study design to achieve a holistic perspective. Two data sets informed the case analysis - a survey of the online support team members and institutional data regarding online student performance.

Online Support Team Survey. An anonymous, online survey instrument with two quantitative questions and ten qualitative questions was designed (Appendix 1) and received human subjects board approval. The questions were developed with three members of the online support team who participated in the crisis response. Their experiences informed what questions would generate meaningful responses across the team. A researcher familiar with, but not part of, the online support team coordinated the survey efforts so team members could feel comfortable offering their honest feedback. An invitation to participate was sent to all online support team members in mid-spring 2018. Out of 24 team members, 15 responded to the survey.

Simple counts and frequencies were performed for the two quantitative questions. Qualitative data was analyzed using a constant comparison technique (Creswell \& Poth, 2018). Descriptive and in vivo codes comprised the first cycle of coding for each question, with a second cycle generating broader themes (Saldaña, 2016). Meta-themes were developed across all questions to better understand and apply the findings. To assist with trustworthiness, Yin (2018) recommended that a key informant examine the analysis to increase validity. The researcher met with a member of the online support team to discuss the initial themes and ensure accurate interpretation. In addition, a final draft of the manuscript was provided to three online support team members for feedback and to ensure that no participants could be identified based on the information shared. References to any specific situations were not reported to further protect participants' identities.

Institutional Data. Institutional data was requested for the fall terms of 2017, 2016, and 2015 so any differences in course performance or completion could be determined between the crisis term and previous fall terms. Course grades and course completion data for all online students were provided in categorical format so analysis included descriptive statistics and comparisons using a chi squared test.

\section{Limitations}

There are limitations of the study that must be considered. Case study research necessarily limits what is studied to a specific context and phenomena (Yin, 2018). This study involves a unique situation that may not transfer to other contexts. Care must be taken when reviewing the details of this case for its applicability to other institutions and situations. In addition, the use of survey methods as a data collection tool does not allow the opportunity for follow-up questions with participants. It is possible that the full depth and breadth of participant experiences are not captured in this study. Finally, researcher subjectivity is an acknowledged challenge for qualitative 
methods (Creswell \& Poth, 2018). While strategies were used to reduce researcher bias, it still may have some influence on the findings.

\section{Results}

\section{Overall Student Performance and Enrollment}

Despite the large-scale disaster, a majority of online students successfully passed their courses by the end of the fall 2017 term. Table 1 provides a comparison of course performance and completion between fall 2017 and the previous two fall terms.

Table 1.

Course Performance and Completion for the 2015, 2016, and 2017 Fall Terms

\begin{tabular}{lllll} 
Term & Pass $(\mathrm{A}, \mathrm{B}, \mathrm{C}, \mathrm{D})(\mathrm{n})$ & Fail $(\mathrm{F})(\mathrm{n})$ & $\begin{array}{l}\text { Incomplete } / \\
\text { Withdrew }(\mathrm{n})\end{array}$ & $\mathrm{N}$ \\
\hline Fall 2017 & $87 \%(16,844)$ & $7 \%(1,385)$ & $6 \%(1,226)$ & 19,455 \\
Fall 2016 & $87 \%(14,786)$ & $6 \%(1,072)$ & $7 \%(1,124)$ & 16,982 \\
Fall 2015 & $86 \%(13,773)$ & $8 \%(1,225)$ & $7 \%(1,116)$ & 16,114
\end{tabular}

While statistically significant differences were found between the different terms $(p<.001)$, there were no practical differences identified. Although more students enrolled in fall 2017 term courses, they performed similarly to students enrolled in online courses for previous fall terms. They also had similar rates of receiving incompletes or withdrawing from courses across all terms. Additionally, no differences were found for course format (15-week versus 7B) in the fall 2017 term.

\section{Online Support Team Experiences}

The online support team regularly provides resources and services for both faculty and students. After the hurricane, which hit during the busiest time of the term, team members added to their list of responsibilities by also performing crisis response activities. Participants identified how many weeks they worked more than 40 hours in order to implement the crisis response plan while still providing regular term support. Eight participants reported working overtime for one to two weeks while another six reported overtime hours for seven to eight weeks. One participant reported working overtime for 11 to 12 weeks.

Participants were asked a series of open-ended questions to better understand their experiences with the crisis response. Across all qualitative questions, the 15 participants provided a total of 313 unique comments. Five meta-themes were identified, and Table 2 illustrates definitions, sample quotes, and a total number of comments offered. Along with the five metathemes, a few important ideas also emerged. These ideas are explored in each of the following sections. 


\section{Table 2.}

\section{Meta-Themes}

\begin{tabular}{|c|c|c|c|}
\hline Meta-Themes & Constructed Meaning & Sample Quotes & $\begin{array}{l}\text { Number of } \\
\text { Comments }\end{array}$ \\
\hline $\begin{array}{l}\text { Data } \\
\text { Management }\end{array}$ & $\begin{array}{l}\text { All processes designed to support } \\
\text { the collection, analysis, and } \\
\text { sharing of data such as creating } \\
\text { forms, collecting data, and } \\
\text { verifying the data }\end{array}$ & $\begin{array}{l}\text { "So much data, and all manually entered that then had to } \\
\text { be reconciled and rechecked at several levels, then } \\
\text { cleaned, corrected, and checked again as problems were } \\
\text { identified." }\end{array}$ & 80 \\
\hline Communication & $\begin{array}{l}\text { The sharing of information, both } \\
\text { internally and externally, } \\
\text { throughout the process including } \\
\text { meetings, sending information via } \\
\text { email, answering questions, etc. }\end{array}$ & $\begin{array}{l}\text { "There was a lot of communication that took place, some } \\
\text { of it was confusing because things were still being } \\
\text { figured out." } \\
\text { "The registrar's office and our office quickly met and got } \\
\text { on the same page. Once they understood the problems } \\
\text { we were facing and we understood theirs we were able to } \\
\text { meet regularly and work through all of the issues." }\end{array}$ & 74 \\
\hline Challenges & $\begin{array}{l}\text { The barriers encountered when } \\
\text { creating a crisis response such as } \\
\text { having to adapt to frequent } \\
\text { changes, lack of an existing plan, } \\
\text { increased workload, and stress } \\
\text { from both the job and the personal } \\
\text { impact of the hurricane }\end{array}$ & $\begin{array}{l}\text { "Many students made mistakes and assumptions that we } \\
\text { didn't predict. They sent the emails to each other, not } \\
\text { understanding that the emails were for specific courses. } \\
\text { Some students heard about the extra semester but their } \\
\text { faculty didn't choose to participate, and they tried to } \\
\text { register using links from other courses. All of these } \\
\text { issues had to be analyzed and sorted through daily." } \\
\text { "The challenge I encountered in my work stemmed from } \\
\text { issues that were happening outside of work. I had to } \\
\text { devote time to both my job and to helping friends and } \\
\text { loved ones bounce back after their homes were nearly } \\
\text { destroyed." }\end{array}$ & 62 \\
\hline $\begin{array}{l}\text { Task } \\
\text { Management }\end{array}$ & $\begin{array}{l}\text { Traditional academic term } \\
\text { responsibilities as well as new } \\
\text { ones generated because of the } \\
\text { hurricane. Does not include data } \\
\text { management activities. }\end{array}$ & $\begin{array}{l}\text { "None of the tasks I performed were exactly outside of } \\
\text { my normal set of tasks. They were tasks that I normally } \\
\text { do at the beginning of a semester and at the beginning of } \\
\text { the } 7.5 \text { week courses. However there were more of them } \\
\text { and there were more questions and requests for support } \\
\text { than there is in a usual semester." }\end{array}$ & 51 \\
\hline Support & $\begin{array}{l}\text { The types of support, and lack of } \\
\text { support, exhibited and extended } \\
\text { during the crisis response such as } \\
\text { good internal teamwork, feelings } \\
\text { of support from others, and a lack } \\
\text { of support from external units }\end{array}$ & $\begin{array}{l}\text { "We also had each other's back, and would take turns / } \\
\text { take over on some of the more wearing tasks so others } \\
\text { could take a break or at least switch to a different portion } \\
\text { of the web of issues we were dealing with." } \\
\text { "Lack of responsiveness from other university } \\
\text { departments or processes. Lack of willingness from other } \\
\text { university departments or processes to adjust their day to } \\
\text { day workload to accommodate the emergency response." }\end{array}$ & 46 \\
\hline
\end{tabular}


Developing Work-around Strategies. Participants identified data management as the most significant complication during the crisis response. Due to institutional policies, the online support team did not have regular access to a critical campus database containing student information. The office managing the database had a policy of providing information within two weeks of a request and they would not make an exception to their two-week policy for the crisis response. Since no formal crisis plan existed for online students, the managing office was not mandated to assist. The lack of voluntary collaboration prompted participants to collect data by hand from almost a thousand students. A number of errors were made during the data entry process and the Registrar sent back incorrect information daily so team members could make updates. Participants mentioned these problems multiple times across questions and lamented the lack of assistance from the database office. The members felt that their stress levels and workloads would have improved if other campus offices were more cooperative during the crisis.

Each time participants encountered an obstacle within the crisis response such as the database access issue, they had to create solutions either through their own ingenuity or by appealing to individuals they each knew personally. If they could not gain support from someone in a leadership position, the team members used their personal networks to find other solutions such as asking a lower level staff member to provide assistance. These strategies helped the team accomplish goals but required a tremendous amount of effort that could have been directed to other crisis activities.

Providing Increased Support to Students and Faculty. Alongside solving crisis-related problems, faculty and students needed additional technological, procedural, and emotional support during the crisis. Participants, who were in regular contact with each group, reflected on the challenges they observed throughout the crisis response period. For the faculty, most of the observations focused on the increased workload and lack of instructor experience with compressed courses. As one participant explained, "If they hadn't taught a 7.5-week course before, it was hard to adapt the course material to a shorter time frame in the time that they had to adjust." Another issue observed for the faculty was communication with academic leadership. A participant shared that "Communication to and from their department chairs and deans seemed to be difficult for everyone to get onto the same page with the constantly changing information." The participants had to frequently troubleshoot the mixed messages and identify accurate information so faculty could move forward with course planning. Finally, participants noted that some faculty experienced damage to their personal property from the hurricane and had a harder time focusing on work responsibilities. The participants had to provide additional support for these individuals so courses would be ready for students.

Participants identified two primary challenges for students that needed extra time and attention. The first challenge was students' struggles to address administrative issues such as completing the correct processes to enroll in the 7B courses, providing accurate personal information, and understanding that they could enroll only if the instructor chose to offer the course in the 7B format. Because the format change was voluntary for faculty, students could have one course that changed to the 7B format but another course that remained in a 15-week format, leading to confusion. One participant explained, "The students that assumed their courses were going to be starting in October may have not done required work in their [15-week] courses."

The second challenge emphasized helping students adjust to the shorter course format while they also dealt with issues arising from the hurricane's impact. One participant observed "students that were effected by Harvey had issues with the technology that is required to be 
successful in an online class, such as having a reliable internet connection and a computer to work on." These students had to locate internet services so they could access courses, then adapt to the compressed time for course activities. It should be noted that three participants did not have a good sense of how students were impacted. Only participants who had direct and sustained responsibilities for crisis activities could readily identify challenges experienced by students.

Positive Outcomes. Overall, participants shared positive reflections about their role in the crisis response. They strongly believed that their teamwork and willingness to help each other led to the success of keeping online students enrolled in courses. The word "proud" was used multiple times and described both their feelings towards the team's efforts but also towards the institution for considering the needs of online students. The "students first" sentiment was a consistent message throughout their comments, with participants sharing that they would repeat the hard work all over again if it meant being able to help students.

Advice for Crisis Planning. Participants offered advice on how to prepare for a future crisis involving online students. Most of their ideas focused on assessing what occurred and developing a plan that would address the challenges experienced, which is aligned with Zdziarski's (2006) model. As one participant noted, "The university has plans in place for disasters, however, they do not typically include any planning for online students. The assumption is that online resources are not impacted by physical disasters, but that couldn't be further from the truth." Participants also wanted to find out what happened to students such as how many completed their courses compared to normal academic terms. While this information was not available initially, later reporting from the institution did provide a sense of closure for the participants and helped them understand the scope of their efforts.

Finally, participants encouraged others on campus to extend more support during crisis response efforts. One participant shared observations of the mixed reaction to the compressed course option offered to online students:

In many ways, I felt that we were caught in the middle of a project that half of our school supported and the other half opposed. This was a difficult place to find ourselves in. I heard faculty in favor of this [the 7B course option], and I heard faculty in strong opposition. I heard public, negative comments from senior leadership in the Colleges and in Academic Affairs, but at the same time, I heard gratitude from the students. This was a divisive initiative and after all the work we put into it, it was disheartening to know that many didn't even support what we had been asked to do. This was demoralizing.

Other participants encouraged more flexibility with job requirements such as being able to temporarily work from home, having some regular tasks deferred during the crisis period, and having access to additional staff resources such as part-time workers being able to work full-time hours or borrowing workers from other areas to assist with the increase in responsibilities.

\section{Discussion}

Similar to other studies detailing crisis events, this research covers the response and recovery efforts at one institution when students experienced a crisis. The study does fill a gap in the literature, however, by highlighting the needs of online students while also contributing ideas for planning and mitigation processes, an essential but often neglected step in crisis management in higher education (Zdziarski, 2006). Crisis management planning should address rapid 
communication and decision-making, clear priorities, support from relevant units, and training for faculty who need to adapt their instruction (Bates, 2013; Camille et al., 2008; Day, 2015; SchWeber, 2008; Shaw, 2017). This case study supports these recommendations by reporting on the challenges and successes encountered by the online support team leading the crisis response.

While there was no road map for the online support team to follow during the crisis in this case study, their approach of supporting each other and prioritizing student needs helped them succeed. And when they encountered obstacles, team members created work-around strategies when they could not leverage formal organizational channels. The team members also found ways to support both faculty and students when they were adapting to the compressed course demands. Their collective efforts helped retain hundreds of students and emphasize the unique needs of the online population to the rest of the campus community.

\section{Implications}

Several recommendations inform the planning and mitigation of crisis situations for online students. Each recommendation is further explained in the following sections.

Recognize Online Students as an Essential Part of the Campus Community. During crisis planning, campus units and leaders work together to develop and train for response to a variety of scenarios (Zdziarski, Dunkel, \& Rollo, 2007). These scenarios, however, often focus solely on the physical campus. The growth of distance education requires campus leaders to think more broadly about crisis response. In this case study, approximately $80 \%$ of the institution's online enrollment was impacted by severe flooding and was at risk for dropping courses. Having this kind of mass withdrawal could have resulted in millions of dollars in lost revenue for the institution along with other problems such as long-term student retention. Online students must become more than an afterthought. This study demonstrates that if online students are overlooked, leaders can put the health of an institution at risk.

Understand Online Student Demographics. To prepare more effectively for crises that impact online students, campus leaders should get to know their online student population and identify ways they could be at risk. For instance, understanding where online students reside geographically could help leaders quickly identify what portion of the population would be impacted by a disaster such as a weather event, pandemic, or terrorist situation. Even in a smallscale crisis, knowing where online students live would help campus representatives reach out to them quickly. It also may be helpful to understand what academic majors have large online student enrollment and whether or not online students are employed or have dependents. This information could lead to directed communication and targeted resources to support the unique needs of online learners after a crisis.

Create a Crisis Team for Online Students. Campus leaders should invite any units that serve the online student population to brainstorm possible crisis scenarios and develop strategies to mitigate the scenarios. These units should primarily address academic issues such as enrollment, course management, instruction, and technological support. Human resources personnel could be helpful for training, communication, and assessment of crisis plans (Wang \& Hutchins, 2010). They could also develop strategies for temporarily assigning staff to assist the crisis response and offering counseling resources to personnel during the crisis. One last consideration should be to include a member of the student affairs division on the crisis team in order to support nonacademic needs such as advising, counseling, and accessing emergency funding. 
Identify Possible Crisis Command Centers. Similar to crises occurring on a physical campus, one location for crisis response should be designated and all communication and decisionmaking should occur through this command center (Zdziarski et al., 2007). For instance, if a disaster occurs in the middle of an academic term, the faculty may be the primary group responding to student needs. In this scenario, the Provost's office would be a good command center so immediate support and advice could be offered to faculty. Other representatives assigned to the crisis team could temporarily relocate to the Provost's office so they could all work together on-site. Having everyone come to the same location would encourage consistent communication, identification of emerging problems, and authority to quickly create and apply solutions. In addition, embedding a senior campus leader with the team for the first few days could promote the quick removal of barriers. For instance, if a senior leader had been available in this case study, the two-week turnaround for database requests may have been waived with a phone call, thereby eliminating a substantial obstacle.

Prepare for Identified Strategies. As this case study illustrated, campuses may identify moving to different course formats as one strategy to assist online students in a crisis. However, this strategy may require additional planning before it can be implemented. For instance, learning management systems may need a special course shell created so it can be quickly applied to existing online courses. Enrollment management staff may need special sections in their databases to accurately record and track individual student records. And developing how-to videos may help faculty navigate both the structure of a different course format as well as ways to provide quality instruction in the new format. Regardless of what strategies are identified, attention should be given to developing the necessary infrastructure before a crisis occurs so institutions can respond quickly and effectively.

Provide Support for Frontline Responders. One last consideration is supporting the frontline responders to the crisis situation. Balancing regular job duties alongside crisis activities can create an intense and pressure-filled environment. Creating a support plan as part of the crisis strategy would ensure that frontline responders have the resources needed to effectively handle the burdens of the situation (Treadwell, 2017). Strategies could include reorganizing regular job responsibilities so some staff are handling those while others can be fully engaged in crisis response; identifying staff from across campus who could temporarily provide support; and increasing part-time staff to full-time hours for the crisis period.

\section{Summary and Future Research}

While many institutions have crisis response plans, these plans are typically focused on students who are on physical campuses. The growing population of online students mandates that campus administrators expand crisis planning to include the needs of distance learners. This case study contributes several lessons for crisis planning such as the documentation of online students being significantly affected by a crisis, the importance of having a strong online support team, and the need for all campus units to work together in a crisis situation. The case study also shares one strategy for addressing a crisis situation for online students and demonstrates that it could be an effective approach in similar contexts.

Future researchers could provide additional guidance for crisis planning such as identifying what situations may have occurred for online students at other institutions, generating possible scenarios of what could happen to online students to interrupt academic progress, and testing strategies for crisis response and recovery that institutions could implement for their online student populations. And, as more crisis situations impact online students, researchers could share details of what occurred so all institutions can enhance their planning before a crisis occurs. 


\section{References}

Allen, E., \& Seaman, J. (2017). Digital learning compass. Distance education enrollment report 2017. Online Learning Consortium. https://onlinelearningconsortium.org/read/digitallearning-compass-distance-education-enrollment-report-2017

Bates, R. (2013). Institutional continuity and distance learning: A symbiotic relationship. Online Journal of Distance Learning Administration, 16(4), 1-7.

Camille, J., Dennis, R., Jackson, M., \& Kenney, C. (2008). Academic and student affairs issues post Hurricane Katrina. Community College Journal of Research and Practice, 32(3), 235-250. https://doi.org/10.1080/10668920701875933

Catullo, L. A., Walker, D. A., \& Floyd, D. L. (2009). The status of crisis management at NASPA member institutions. NASPA Journal, 46(2), 301-324.

Creswell, J. W., \& Poth, C. N. (2018). Qualitative inquiry and research design (4th ed.). Sage.

Day, T. (2015). Academic continuity: Staying true to teaching values and objectives in the face of course interruptions. Teaching and Learning Inquiry: The ISSOTL Journal, 3(1), 7589.

Harper, K. S., Paterson, B., \& Zdziarski II, E. (2006). Crisis management: Responding from the heart. NASPA.

Harrington, R., Ramsey, L., \& Varinsky, D. (2017, August 13). Texas, Louisiana begin long recovery from catastrophic flooding as the remnants of Hurricane Harvey move northeast. Business Insider. https://www.businessinsider.com/tropical-storm-harveyhurricane-updates-map-texas-where-landfall-damage-2017-8

L'Orange, H. P. (2010). Impact of incidents on enrollments at higher education institutions. New Directions for Institutional Research, 2010(146). https://doi.org/10.1002/ir.346

Meyer, K. A., \& Wilson, J. L. (2011). The role of online learning in the emergency plans of flagship institutions. Online Journal of Distance Learning Administration, 4(1). http://www.westga.edu/ distance/ojdla/spring141/meyer_wilson141.html

Miller, T. (2018). Crisis as a driver for innovation: The " $7 B$ " semester as a response to Hurricane Harvey. SHSU Online. http://shsuorsp.maps.arcgis.com/apps/Cascade/index.html?appid=b24c0f6960b24b3ab112c8881151 $\underline{\mathrm{a} 2 \mathrm{~d} 9}$

Mitroff, I. I., \& Anagnos, G. (2001). Managing crisis before they happen. AMACOM Books.

Regehr, C., Nelson, S., \& Hildyard, A. (2016). Academic continuity planning in higher education. Journal of Business Continuity \& Emergency Planning, 11(1), 73-84.

Rollo, J. M., \& Zdziarski, E. L. (2007). The impact of crisis. In E. L. Zdziarski, N. W. Dunkel, \& J. M. Rollo (Eds.), Campus crisis management: Comprehensive guide to planning, prevention, response, and recovery. Jossey Bass.

Saldaña, J. (2016). The coding manual for qualitative researchers (3rd ed.). Sage.Sam Houston State University. (2017). Harvey after action review. https://www.shsu.edu/katsafe/documents/Harvey\%20After\%20Action\%20Review\%20(F INAL).pdf 
SchWeber, C. (2008). Determined to learn: Accessing education despite life-threatening disasters. Journal of Asynchronous Learning Networks, 12(1), 37-43. https://files.eric.ed.gov/fulltext/EJ837468.pdf

Shaw, M. D. (2017). Pathways to institutional equilibrium after a campus disaster. Journal of Contingencies and Crisis Management, 25(2), 103-113. https://doi.org/10.1111/1468$\underline{5973.12128}$

SHSU Institutional Effectiveness. (2018). Common data set 2017. Sam Houston State University IE Data Publications. https://www.shsu.edu/dept/institutionaleffectiveness/publications.html

SHSU Online. (2018). Fall 2017 national overview. https://www.shsu.edu/dl_www/maps/maps/2017fall/

Chronicle Almanac. (2018, August 19). Colleges' revenue and expenditures, by sector, FY 2016. The Chronicle of Higher Education. https://www.chronicle.com/article/Colleges$\underline{\text { Revenue-and } / 244168}$

Texas Commission on Environmental Quality. (2018). After action review report. https://www.tceq.texas.gov/assets/public/response/hurricanes/hurricane-harvey-afteraction-review-report.pdf.

Treadwell, K. (2017). Learning from tragedy: Student affairs leadership following college campus disasters. Journal of Student Affairs Research and Practice, 54(1), 42-54. https://doi.org/10.1080/19496591.2016.1206019

Wang, J., \& Hutchins, H. M. (2010). Crisis management in higher education: What have we learned from Virginia Tech? Advances in Developing Human Resources, 12(5), 552-572. https://doi.org/10.1177/1523422310394433

Yin, R. K. (2018). Case study research and applications: Design and methods. Sage.

Zdziarski, E.L. (2006). Crisis in the context of higher education. In K.S. Harper, B. G. Paterson, \& E. L. Zdziarski (Eds.), Crisis management: Responding from the heart (pp. 3-24). NASPA.

Zdziarski, E. L., Dunkel, N. W., \& Rollo, J. M. (2007). Campus crisis management: A comprehensive guide to planning, prevention, response, and recovery. Jossey Bass. 


\section{Appendix 1 \\ Staff Survey}

- Please describe what tasks you were involved in during the Hurricane Harvey response.

- Please describe what additional tasks you performed during the fall 2017 term that were outside of your normal set of tasks.

- What is the primary challenge you encountered in your work because of Hurricane Harvey?

- In what ways were you supported in your work during this period of time?

- What would have been helpful to your work during this period of time that you did not have?

- Based on your work with the Hurricane Harvey response, what seemed to be the biggest challenge for your office?

- How would you describe the communication between the institution and you regarding the Hurricane Harvey response?

- Based on your work with the Hurricane Harvey response, what seemed to be the biggest challenge for faculty members that you observed?

- Based on your work with the Hurricane Harvey response, what seemed to be the biggest challenge for students that you observed?

- What else would you like to share regarding the Hurricane Harvey response for online students? 